\title{
Evaluation of Quantitative PCR Measurement of Bacterial Colonization of Epithelial Cells
}

\author{
MARCIN T. SCHMIDT*, AGNIESZKA K. OLEJNIK-SCHMIDT, KAMILA MYSZKA, \\ MONIKA BORKOWSKA and WŁODZIMIERZ GRAJEK
}

Department of Biotechnology and Food Microbiology, Poznań University of Life Sciences, Poznań, Poland

Received 8 January 2010, revised 8 March 2010, accepted 12 March 2010

\begin{abstract}
Microbial colonization is an important step in establishing pathogenic or probiotic relations to host cells and in biofilm formation on industrial or medical devices. The aim of this work was to verify the applicability of quantitative PCR (Real-Time PCR) to measure bacterial colonization of epithelial cells. Salmonella enterica and Caco-2 intestinal epithelial cell line was used as a model. To verify sensitivity of the assay a competition of the pathogen cells to probiotic microorganism was tested. The qPCR method was compared to plate count and radiolabel approach, which are well established techniques in this area of research. The three methods returned similar results. The best quantification accuracy had radiolabel method, followed by qPCR. The plate count results showed coefficient of variation two-times higher than this of qPCR. The quantitative PCR proved to be a reliable method for enumeration of microbes in colonization assay. It has several advantages that make it very useful in case of analyzing mixed populations, where several different species or even strains can be monitored at the same time.
\end{abstract}

K e y w ord s: adhesion, colonization, plate count, Real-Time PCR, radiolabel

\section{Introduction}

Adhesion to extracellular matrix and cells is often an important step in the infection process of pathogenic bacteria, which can be also an initial stage of invasion leading to colonization (Pizarro-Cerdá and Cossart, 2006). Similarly, one of the mechanisms underlying beneficial effects of probiotic bacteria is their ability to adhere to mucus and/or intestinal epithelial cells. Although probiotic's adhesion is not required for their competence to cause beneficial effects for the host their ability of gastrointestinal tract colonization is considered as a worthy trait (Sánchez et al., 2008). Also formation of biofilms in industrial equipment (Kumar and Anand, 1998) and indwelling medical devices (Donlan, 2001) is mediated through the adhesion of microorganisms to solid surfaces. Adhesion initiates colonization determining positive and negative trait of a strain making it important for human. Since it is not possible to estimate theoretically the adhesion of a cell to other cell or substratum the process has to be measured empirically.

This paper describes the comparison of two well established and widely used techniques (plate count and radiolabeling) to a novel approach which uses quantitative PCR (Real-Time PCR) in analysis of colonization of tissues by microorganisms. As an experimental model we chose Caco-2 cells that spontaneously differentiate into villous enterocytes (Sambuy et al., 2005) and provide a useful in vitro model to study pathogens and probiotics that interact with human intestinal epithelia (Curfs et al., 1995; Finlay and Falkow, 1990; Lee et al., 2003). For the test bacteria Salmonella enterica was selected as salmonellosis remains a major foodborne disease (Voetsch et al., 2004) and probiotic Lactobacillus rhamnosus GG (Alvarez-Olmos and Oberhelman, 2001) to perform a competition assay testing specificity of the assays.

\section{Experimental}

Materials and Methods

Bacterial strains. Salmonella enterica subsp. enterica serovar Typhimurium ATCC 14028 was obtained from the LG Protochem (Poland) and Lactobacillus rhamnosus GG (ATCC 53103) was isolated from

\footnotetext{
* Corresponding author: M. Schmidt, Department of Biotechnology and Food Microbiology, Poznań University of Life Sciences, Wojska Polskiego 48, 60-627 Poznań, Poland; phone: (+48) 6184660 24; fax: (+48) 6184660 03; e-mail: mschmidt@up.poznan.pl
} 
dietary supplement (Dicoflor, VITIS Pharma, Poland). The bacteria were grown in Brain and Heart Infusion broth (BHI; Oxoid) at $37^{\circ} \mathrm{C}$ in anaerobic conditions (Anaerocult A, Merck, Poland) for 18-20 h before use.

To label bacteria, methyl- $\left[{ }^{3} \mathrm{H}\right]$-thymidine $(60-90$ $\mathrm{Ci} / \mathrm{mmol}, 1 \mathrm{mCi} / \mathrm{ml}$; Hartmann Analytic GmbH, Germany) was added to the medium at a volume of $5 \mu \mathrm{l} / \mathrm{ml}$ of medium. After 18-20 hours of growth, the bacteria were washed twice with sterile Hank's Buffered Salts Solution (HBSS) and resuspended in the same buffer.

Intestinal cell culture. Caco- 2 cell cultures were used in the adhesion assay (Sambuy et al., 2005). This human colon adenocarcinoma cell-line was obtained from the European Collection of Cell Cultures (ECACC). Cells were cultured in Dulbecco's modified Eagle's minimal essential medium (Sigma) that contained $10 \%(\mathrm{v} / \mathrm{v})$ heat-inactivated fetal calf serum (Gibco-BRL) and 1\% non-essential amino acids (Gibco-BRL). Cells were grown at $37^{\circ} \mathrm{C}$ in an atmosphere of $10 \% \mathrm{v} / \mathrm{v} \mathrm{CO}_{2}$ in air. For the adhesion assay, monolayers of Caco-2 cells were prepared in PTFE filter $(1 \mu \mathrm{m}$ pore size $)$ inserts for 6 -well tissue-culture dishes (Millipore) by inoculating $2 \times 10^{6}$ viable cells (passage no 49-52) per insert in $2.0 \mathrm{ml}$ culture medium. The cells were cultivated for three weeks to allow differentiation. Medium was replaced every 2 days.

Adhesion/invasion assay. Twenty one-days-postconfluent Caco-2 cell monolayers were washed once with $1 \mathrm{ml}$ sterile HBSS before the adhesion assay. Bacteria at concentrations of approximately $5 \times 10^{8} \mathrm{cfu} / \mathrm{ml}$ were added to each insert in $2.0 \mathrm{ml}$ (total volume) HBSS and incubated at $37^{\circ} \mathrm{C}$ in an atmosphere of $10 \%$ (v/v) $\mathrm{CO}_{2}$ in air. After $60 \mathrm{~min}$ incubation, monolayers were washed three times with sterile HBSS to remove free bacterial cells. Amount of adhered bacterial cells was estimated from radioactivity, by plate counting and quantitative PCR.

Radioactivity counting. Radiolabeled bacteria in amount initially added for adhesion and washed Caco-2 monolayer with adhered radiolabeled bacteria were lysed in $0.9 \mathrm{ml}$ of $1 \% \mathrm{SDS}$, then $0.1 \mathrm{ml}$ of $1 \mathrm{M}$ $\mathrm{NaOH}$ was added and the lysate was incubated overnight at $60^{\circ} \mathrm{C}$ to complete lysis. The radioactivity of the lysed suspension was measured by liquid scintillation in Beckmann LS6500 after addition of HionicFluor scintillation cocktail (Perkin-Elmer, Poland).

Plate counting. Washed Caco- 2 cells with adhered bacteria were liberated from insert membrane by $0.25 \%$ Trypsin, $0.1 \%$ EDTA in HHBSS (Sigma) treatment for $5 \mathrm{~min}$ at $37^{\circ} \mathrm{C}$, the enzyme was inactivated with Soybean trypsin inhibitor (Sigma). The cell suspension and bacteria in an amount initially added for adhesion were serial-diluted in peptone water (Oxoid) and plated on SS Agar (Merck). The SS Agar does not support growth of $L$. rhamnosus. The first dilution was severely vortexed to facilitate osmotic lysis of Caco-2 cells and release bacteria in case of invasion. After $24 \mathrm{~h}$ incubation in $35^{\circ} \mathrm{C}$ black colonies were counted.

Quantitative PCR (qPCR). Bacteria in an amount initially added for adhesion and washed Caco-2 cells with adhered bacteria were lysed in $1 \mathrm{ml}$ of $50 \mathrm{mM}$ Tris $\mathrm{pH} 7.5,50 \mathrm{mM} \mathrm{NaCl}, 5 \mathrm{mM}$ EDTA, $1 \%$ SDS with proteinase K $(50 \mu \mathrm{g} / \mathrm{ml}$; Sigma $)$ and RNase A $\left(10 \mu \mathrm{g} / \mathrm{ml}\right.$; Sigma) at $56^{\circ} \mathrm{C}$ for $1 \mathrm{~h}$. The cell lysates were extracted twice with equal volume of buffered phenol-chloroform-isoamyl alcohol mixture (25:24:1), then once with chloroform. Nucleic acids were precipitated with three volumes of $100 \%$ ethanol, 0.1 volume of $3 \mathrm{M}$ sodium acetate $\mathrm{pH} 5.2$ and $20 \mu \mathrm{g}$ glycogen. Pellets were dissolved in TE buffer $(10 \mathrm{mM}$ Tris $\mathrm{pH}$ 7.5, $0.1 \mathrm{mM}$ EDTA). Absolute quantification of bacteria was performed with Real-Time PCR (ABI 7500 SDS; Applied Biosystems) using BACIdent Salmonella ssp. Kit (Eurofins GeneScan GmbH, Germany) in conditions recommended by kit manufacturer. The kit employs TaqMan chemistry for amplicon detection. It is designed for quantitative analysis and includes internal control. Serial dilution of DNA isolated from bacteria in amount initially added to Caco-2 monolayer was used for generation of standard curve.

Statistics. Each assay was performed in triplicate. Differences between measurements were examined for significance by Student's t-test after analysis of variance with Statistica software (v6; StatSoft). P $>0.05$ was considered to be statistically insignificant.

\section{Results}

Comparison of colonization assays. Enumeration of $S$. enterica colonizing (adhering and/or invading) Caco- 2 cells was performed by three techniques: radiolabeling, plate count, and quantitative PCR (Real-Time PCR). The two foremost techniques are well established ones and widely used in study of bacterial adhesion to epithelial cells (Lee et al., 2000; Ouwehand et al., 2003; Tallon et al., 2007). Results generated by them allow to evaluate the usefulness of Real-Time PCR in this assay. The determined S. enterica colonization of Caco-2 cells measured with the three different methods should give equal results. As the methods return values that cannot be directly compared (counts per minute, $\mathrm{CFU}$, and $\mathrm{C}_{\mathrm{T}}$ ) the specific measures were normalized to relative count assuming that amount of bacteria introduced to Caco- 2 cell culture at the beginning of the assay was $100 \%$. The relative count of $S$. enterica colonizing enterocytes measured by radiolabeling, plate count and qPCR were $2.66 \%(\mathrm{SD}=0.05), 4.15 \%(\mathrm{SD}=1.89)$, and $4.29 \%$ $(\mathrm{SD}=0.75)$, respectively (Fig. 1$)$.

To test the sensitivity and selectivity of the assays the competition of $S$. enterica with $L$. rhamnosus GG 


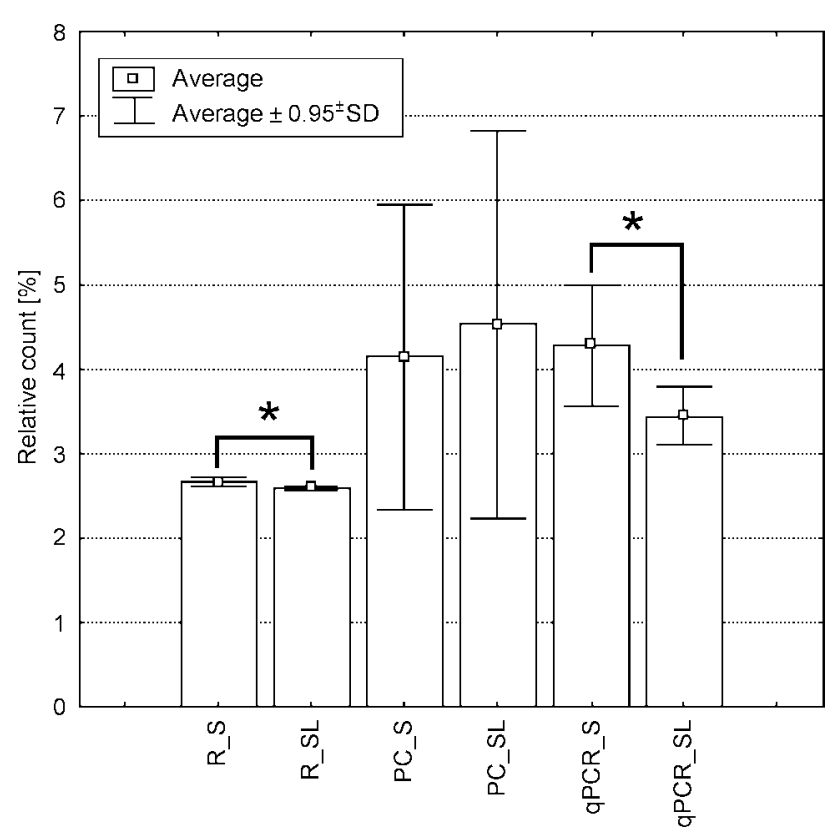

Fig. 1. Relative counts of $S$. enterica subsp. enterica cells colonizing differentiated Caco-2 cells without (S) or in competition to L. rhamnosus GG (SL).

Colonization was measured by three independent methods: radiolabeling (R), plate count (PC) and quantitative PCR (qPCR). The bars indicate relative amount of $S$. enterica colonizing Caco-2 cells, statistically significant differences are depicted with asterisks $(\mathrm{P}<0.05)$.

for adhesion was performed (Fayol-Messaoudi et al., 2007). The relative counts of $S$. enterica colonizing enterocytes in presence of L. rhamnosus GG were measured with the same three techniques, giving: $2.59 \%(\mathrm{SD}=0.02), 4.53 \%(\mathrm{SD}=2.40)$, and $3.45 \%$ $(\mathrm{SD}=0.36)$, respectively for radiolabeling, plate count and qPCR (Fig. 1). The differences between $S$. enterica colonization without and with competition with probiotic bacterium were statistically significant for data obtained from radiolabel and qPCR assays $(\mathrm{P}<0.05)$.

Quantification accuracy. Variability of the normalized quantity between the replicates can be used as a measure of the quantification accuracy - the lower the variability between replicates the higher the accuracy of quantification. Coefficients of variation (CV) were calculated from relative quantity of bacteria in the replicates. Comparison of $\mathrm{CV}$ values between individual methods of analysis showed markedly highest coefficients of variation in the plate count, and the lowest for radiolabeling. The $\mathrm{CV}$ values were $1.84 \%$ and $0.66 \%$ for radiolabeling, $45.76 \%$ and $53.12 \%$ for plate counting, $17.70 \%$ and $10.45 \%$ for qPCR (each for direct colonization and competition, respectively).

\section{Discussion}

Relatively few methods are available for colonized bacteria enumeration, despite adhered or invaded (Vesterlund et al., 2005). Most of them are based on culturing (plating) (Sherman et al., 2005) and microscopic studies after fixation and staining (Buck et al., 2005). However, these methods can not be applied to mixed populations. For selectivity in multi-species studies bacteria are often radiolabeled (Lee et al., 2000). Fluorescent stains are also used for bacteria labeling for subsequent selective enumeration (McFeters et al., 1995; Bosch et al., 2003). Similarly fluorescent in situ hybridization (FISH) allows simultaneous enumeration of several species (Maré et al., 2006; Wang et al., 2009), however the microscope-based techniques require computer-assisted picture analysis software or are laden with human-error of manual counting.

Plating is laborious and requires that microbes are released from tested cells for preparing appropriate serial dilutions. They must remain cultivable after that process. In case of Gram-positive bacteria and yeasts epithelial cells monolayer can be easily disrupted with nonionic detergent. However Gram-negative bacteria may not withstand such detergent treatment, and use of mild dissociation solution (i.e. trypsin-EDTA solution) may be necessary. When colonization of one bacterial strain is examined in an environment where other bacteria are present, plating can be applied for enumeration, however selective media must be used. Yet, even on selective media various species can produce similar colonies difficult to differentiate (Hartemink and Rombouts, 1999; Lee and Lee, 2008), and selective agents can prevent or inhibit the recovery and subsequent multiplication of injured cells leading to inconsistent results (Blackburn and McCarthy, 2000). The plating method is also not sensitive enough to detect small differences in adhesion properties of certain strains (Tumola, 1999). This was confirmed by high coefficient of variation for this method and non-significant difference for results of colonization without and with competition with $L$. rhamnosus GG. Despite of the weaknesses of this technique it has certain advantages. It is inexpensive and directly detects a number of microbial cells.

The most consistent results were obtained using enumeration by radiolabeling. This may be a result of low handling of the samples. The adhered bacteria after wash steps were directly lysed together with epithelial cells. However this assay disregards bacterial cells multiplication during assay because the radioisotope level (incorporated into genetic material) stays constant in bacterial population throughout whole assay, despite a possible increase in cell number. Yet, the nature of radioactivity does not allow multiple labeling and only one species can be analyzed at a time. The use of isotopes rouses safety concerns in general and ethical issues in the case of studies involving animals.

Quantitative PCR (Real-Time PCR) generated results are more similar to this obtained by plate count 
than radiolabel. This is not unusual since both methods detect population growth during assay. However qPCR returns results with better quantification accuracy than plate counting. Quantitative PCR have several important advantages over both plate counting and radiolabeling. It allows to enumerate an unlimited number of species in the same sample (either live or dead), experimentally introduced or native microflora regardless of sample source. The method is safe and does not have to be performed directly after adhesion assay. Even formalin-fixed and paraffin-embedded tissues can be used. However, several technical issues have to be kept in mind.

For quantitative PCR a first step is DNA isolation. In case of Gram-negative bacteria both cells monolayer and microorganisms can be simply disrupted by addition of detergent. To facilitate isolation of DNA from Gram-positive bacteria and yeasts cell wall disruption is often necessary (Kumar, 2008; Fliss et al., 1991; Niwa et al., 2005; Phalip et al., 2004). Silicabased or anion-exchange columns provide fast and easy method for purification of total DNA for reliable PCR. However when minute amount of start material is used a carrier DNA should be added to lysis buffer to ensure optimal binding conditions. On the other hand since epithelial cells' DNA co-purifies with microbial DNA the sample can exceed capacity of DNA purification column. Classical DNA isolation methods (like this used in this research) can be successfully applied in the assay. However they are usually time-consuming, laborious, and may result in higher variation of results.

In case of studies involving in vitro cultured cells use of specific starters targeted to single copy gene of cells' DNA the ratio of adhered microorganism to host cells can be easily confirmed or determined. Real-Time PCR has also many additional advantages over other techniques. These are simplicity (no need to post adhesion cultivation and selection of bacteria), specificity (possibility to detect specific strain), selectability (detection of single species or genera from complex consortia) and safety (no need to use of radioisotopes and post adhesion cultivation of pathogenic bacteria). This technique can also be applied to in vivo studies (tissue sections or biopsies) as there is no need to label bacteria or select from mixed populations. The great advantage is possibility to use the Real-Time PCR detection for non-cultivable species. When isolating total RNA and performing reverse transcription specific viable microbes can be detected.

qPCR proved to be very useful in quantitative determination of bacterial colonization of epithelial cells. This assay is sensitive, selective and gives results similar to other widely used ones.

\section{Acknowledgments}

This work was supported by the Polish Ministry of Science and Higher Education grant no N312 047 32/2668 in years 2007-2010.

\section{Literature}

Alvarez-Olmos M.I. and R.A. Oberhelman. 2001. Probiotic agents and infectious diseases: a modern perspective on a traditional therapy. Clin. Infect. Dis. 32: 1567-1576.

Blackburn C.W. and J.D. McCarthy. 2000. Modifications to methods for the enumeration and detection of injured Escherichia coli O157:H7 in foods. Int. J. Food Microbiol. 55: 285-290.

Bosch J.A., E.C. Veerman, M. Turkenburg, K. Hartog, J.G. Bolscher and A.V. Nieuw Amerongen. 2003. A rapid solidphase fluorimetric assay for measuring bacterial adherence, using DNA-binding stains. J. Microbiol. Methods 53: 51-56.

Buck B.L., E. Altermann, T. Svingerud and T.R. Klaenhammer. 2005. Functional analysis of putative adhesion factors in Lactobacillus acidophilus NCFM. Appl. Environ. Microbiol. 71: 8344-8351.

Curfs J.H., J.F. Meis, J.A. Fransen, H.A. van der Lee and J.A. Hoogkamp-Korstanje. 1995. Interactions of Yersinia enterocolitica with polarized human intestinal Caco-2 cells. Med. Microbiol. Immunol. 184: 123-127.

Donlan R.M. 2001. Biofilm formation: a clinically relevant microbiological process. Clin. Infect. Dis. 33: 1387-1392.

Fayol-Messaoudi D., M.H. Coconnier-Polter, V.L. Moal, F. Atassi, C.N. Berger and A.L. Servin. 2007, The Lactobacillus plantarum strain ACA-DC287 isolated from a Greek cheese demonstrates antagonistic activity in vitro and in vivo against Salmonella enterica serovar Typhimurium. J. Appl. Microbiol. 103: 657-665. Finlay B.B. and S. Falkow. 1990. Salmonella interactions with polarized human intestinal Caco-2 epithelial cells. J. Infect. Dis. 162: 1096-1106.

Fliss I., E. Emond, R.E. Simard and S. Pandian. 1991. A rapid and efficient method of lysis of Listeria and other gram-positive bacteria using mutanolysin. Biotechniques 11: 456-457.

Hartemink R. and F.M. Rombouts. 1999. Comparison of media for the detection of bifidobacteria, lactobacilli and total anaerobes from faecal samples. J. Microbiol. Methods 36: 181-192.

Kumar C.G. and S.K. Anand. 1998. Significance of microbial biofilms in food industry: a review. Int. J. Food Microbiol. 42: 9-27.

Kumar J.K. 2008. Lysostaphin: an antistaphylococcal agent. Appl. Microbiol. Biotechnol. 80: 555-561.

Lee H.M. and Y. Lee. 2008. A differential medium for lactic acidproducing bacteria in a mixed culture. Lett. Appl. Microbiol. 46: 676-681.

Lee Y.K., C.Y. Lim, W.L. Teng, A.C. Ouwehand, E.M. Tuomola and S. Salminen. 2000. Quantitative approach in the study of adhesion of lactic acid bacteria to intestinal cells and their competition with enterobacteria. Appl. Environ. Microbiol. 66: 3692-3697. Lee Y.K., K.Y. Puong, A.C. Ouwehand and S. Salminen. 2003. Displacement of bacterial pathogens from mucus and Caco-2 cell surface by lactobacilli. J. Med. Microbiol. 52: 925-930.

Maré L., G.M. Wolfaardt and L.M. Dicks. 2006. Adhesion of Lactobacillus plantarum 423 and Lactobacillus salivarius 241 to the intestinal tract of piglets, as recorded with fluorescent in situ hybridization (FISH), and production of plantaricin 423 by cells colonized to the ileum. J. Appl. Microbiol. 100: 838-845.

McFeters G.A., F.P. Yu, B.H. Pyle and P.S. Stewart. 1995. Physiological assessment of bacteria using fluorochromes. J. Microbiol. Methods 21: 1-13.

Niwa T., Y. Kawamura, Y. Katagiri and T. Ezaki. 2005. Lytic enzyme, labiase for a broad range of Gram-positive bacteria and 
its application to analyze functional DNA/RNA. J. Microbiol. Methods 61: 251-260.

Ouwehand A.C., S. Salminen, P.J. Roberts, J. Ovaska and E. Salminen. 2003. Disease-dependent adhesion of lactic acid bacteria to the human intestinal mucosa. Clin. Diagn. Lab. Immunol. 10: 643-646.

Phalip V., D. Hatsch and J.M. Jeltsch. 2004. Application of a yeast method for DNA extraction associated with database interrogations for the characterization of various filamentous fungi from diseased hop. Biotechnol. Lett. 26: 409-413.

Pizarro-Cerdá J. and P. Cossart. 2006. Bacterial adhesion and entry into host cells. Cell 124: 715-727.

Sambuy Y., I. De Angelis, G. Ranaldi, M.L. Scarino, A. Stammati and F. Zucco. 2005. The Caco-2 cell line as a model of the intestinal barrier: influence of cell and culture-related factors on Caco-2 cell functional characteristics. Cell. Biol. Toxicol. 21: 1-26. Sánchez B., P. Bressollier and M.C. Urdaci. 2008. Exported proteins in probiotic bacteria: adhesion to intestinal surfaces, host immunomodulation and molecular cross-talking with the host. FEMS Immunol. Med. Microbiol. 54: 1-17.

Sherman P.M., K.C. Johnson-Henry, H.P. Yeung, P.S. Ngo, J. Goulet and T.A. Tompkins. 2005. Probiotics reduce entero- hemorrhagic Escherichia coli O157:H7- and enteropathogenic E. coli $\mathrm{O} 127: \mathrm{H6}$-induced changes in polarized T84 epithelial cell monolayers by reducing bacterial adhesion and cytoskeletal rearrangements. Infect. Immun. 73: 5183-5188.

Tallon R., S. Arias, P. Bressollier and M.C. Urdaci. 2007. Strainand matrix-dependent adhesion of Lactobacillus plantarum is mediated by proteinaceous bacterial compounds. J. Appl. Microbiol. 102: 442-451.

Tumola E. 1999. PhD thesis. In vitro adhesion of probiotic lactic acid bacteria. University of Turku, Turku, Finland.

Vesterlund S., J. Paltta, M. Karp and A.C. Ouwehand. 2005. Measurement of bacterial adhesion-in vitro evaluation of different methods. J. Microbiol. Methods 60: 225-233.

Voetsch A.C., T.J. Van Gilder, F.J. Angulo, M.M. Farley, S. Shallow, R. Marcus, P.R. Cieslak, V.C. Deneen and R.V. Tauxe. 2004. Food Net estimate of the burden of illness caused by nontyphoidal Salmonella infections in the United States. Clin. Infect. Dis. 38: S127-S134.

Wang B., J. Li, Q. Li, H. Zhang and N. Li. 2009. Isolation of adhesive strains and evaluation of the colonization and immune response by Lactobacillus plantarum $\mathrm{L} 2$ in the rat gastrointestinal tract. Int. J. Food Microbiol. 132: 59-66. 